\title{
STATISTICAL ANALYSIS OF CHEMICALLY TREATED HEMP FIBRE WASTE PARTICLE SIZE DISTRIBUTION AFTER GRINDING
}

\author{
Zane Zelca, Silvija Kukle, Janis Kajaks \\ Riga Technical University, Latvia \\ gusare@inbox.lv
}

\begin{abstract}
The effects of mercerization, traditional silanization and a sol-gel treatment on hemp primary processing waste particle size distribution after grinding with $1 \mathrm{~mm}$ grid and composite maximal tensile strength correlation with waste particle distribution were investigated. The waste was shaken in a sieve shaker by the standard LVS EN 933 (111) using $1000 \mu \mathrm{m}, 500 \mu \mathrm{m}, 355 \mu \mathrm{m}, 150 \mu \mathrm{m}, 90 \mu \mathrm{m}$ sieves. Composites with the fibre content $40 \mathrm{wt} \%$ using LLDPE as a matrix were prepared by two roll mill. A correlation between the waste particle size and the maximum tensile strength of the composite was found - lower maximum tensile strength shows composite with modal fibre size distribution smaller than $90 \mu \mathrm{m}$. With hemp waste particle distribution composite maximum tensile strength differences can be predicted depending on the waste treatment methods.
\end{abstract}

Keywords: hemp fibre waste, particle size distribution, sieve test, composite maximum tensile strength.

\section{Introduction}

Natural fibre filled and reinforced composite (NFC) mechanical properties can vary depending on the fibre quality, treatment, length, matrix properties and other parameters. The change of the fibre length in the process of reinforcing natural fibres can be studied from different aspects - process steps, melt viscosity, fibre type [1], aspect ratio, dispersion, orientation of fibres and loading [2].

The size and shape of particles could influence the composite properties. Larger, more spherical particles will flow more easily than smaller or high aspect ratio particles. Smaller droplet sizes and higher surface charge (zeta potential) will improve suspension and emulsion stability. Size reduction operations applied in technologies such as milling, crushing, homogenization, emulsification, micro fluidization, and others may be monitored by measuring the particle size before and after the process. Non-spherical particles can be described using multiple length and width measures from horizontal and vertical projections [3]. These descriptions can provide the greater accuracy, but are also connected with the greater complexity. Grinding of various natural fillers can be divided in different particle size. A pilot size Szego Mill was used to grind hemp fibres, the results shows that the roller geometry, roller groove structure have the most significant effect on the size distribution and fibre quality [4].

Fibre length in different natural fibre containing composites is studied from various aspects. Natural fibre composites are the cheapest and most widely used biomaterials. Depending on the size of the particles: large particle composites and dispersion-strengthened composites. Normally the matrix has a much lower modulus than the fibre, so it strains more. This occurs at a distance from the fibre. Right next to the fibre, the strain is limited by the fibre [5].

Aspect ratio for fibres (length/diameter), which can be incorporated into the natural fibre/polymer composite is an important factor influencing the mechanical properties of the polymer composites. In a short fibre composite, the tensile load is transferred into fibres from the matrix through shear at the fibre/matrix interface. The fibre length would be much greater than the critical length to allow efficient reinforcement of the natural fibre/polymer composite, such that the majority of the fibres could be loaded as if it were continuous fibres. The study of wood flour/polypropylene (PP) composites made with various sizes of wood particles showed that the aspect ratio, not the particle size, had the greatest effect on the strength and stiffness [6].

It was found that the tensile strength increased for all composites containing hemp fibres $30 \mathrm{wt} . \%$, but the optimal fibre length for hemp and flax fibre comparing 0.25-2 mm was $1 \mathrm{~mm}$ [7]. High quality hemp and primary processing waste with some content of sieves shows different particle distribution sizes after grinding. The fibres more than half of the particles divided into more than $500 \mu \mathrm{m}$, but the waste was ranging from 150 to $355 \mu \mathrm{m}$ using $1 \mathrm{~mm}$ grid [8].

The fibre and matrix interaction can be improved by modifying the filler surface or the matrix. Several treatments have been investigated with varying success. $\mathrm{NaOH}$ pretreatment might be a useful first step in combination with other fibre or matrix modification methods. As a result, the fibre surface 
becomes clean [2]. Alkaline pretreatment of the fibre/filler can be done before to the silane one. Nanoscaled silica, which are suitable for penetration the cell walls of the fibre pores synthesized by sol-gel method can be used [9].

The effects of mercerization, traditional silanization and a sol-gel treatment on hemp primary processing waste particle size distribution after grinding with $1 \mathrm{~mm}$ grid and composite maximal tensile strength correlation with waste particle distribution were investigated in this work.

\section{Materials and methods}

The primary processing waste of hemp variety "Bialobrzeskie" harvested in 2015 in the Vilani district and supplied by the Ltd. "Zalers" (Latvia) was used. The obtained waste consists of shives and less valuable secondary fibres. The weight ratio of waste to shives 1 to 3 .

Hemp waste treatment variants are shown in Tab. 1. Alkalized waste was prepared using $2 \mathrm{wt} \%$ Sodium hydroxide (Enola, ES) solution. Silanized waste was prepared by treated alkalized waste with APTES - (3-Aminopropyl)triethoxysilane $\left(\mathrm{C}_{9} \mathrm{H}_{23} \mathrm{NO}_{3} \mathrm{Si}\right)$ supplied by Sigma-Aldrich (Belgium) or TEOS - tetraethyl orthosilicate, formally named tetraethoxysilane $\left(\mathrm{C}_{8} \mathrm{H}_{20} \mathrm{O}_{4} \mathrm{Si}\right)$ purchased from Alfa Aesar (Germany). Ethanol $\left(\mathrm{C}_{2} \mathrm{H}_{5} \mathrm{OH}\right)$ and Hydrofluoric acid (HF) used in all treatment variants supplied by Enola (ES), Zinc oxide (size $\sim 20 \mathrm{~nm}$ ) and Zinc acetate dihydrate $\left(\mathrm{Zn}(\mathrm{CH} 3 \mathrm{COO})_{2} \cdot 2 \mathrm{H}_{2} \mathrm{O}\right)$ from Lach-Ner (Czech Republic) were used as TEOS sol modifiers.

The hemp waste dried in air chamber at $+105^{\circ} \mathrm{C}$ for $24 \mathrm{~h}$ and crushed with the rotation mill RETSCH ZM-200 equipped with a $1 \mathrm{~mm}$ holes grid to obtain the particle size less than $1 \mathrm{~mm}$ (Fig.1) was prepared for NFC manufacturing.

Hemp waste treatment variants

Table 1

\begin{tabular}{|c|c|l|}
\hline Sample & $\begin{array}{c}\text { 2\% Alcaline } \\
\text { pre-treatment }\end{array}$ & \multicolumn{1}{|c|}{ Treatment } \\
\hline U & - & \\
\hline M & $\mathrm{X}$ & \multicolumn{1}{|c|}{-} \\
\hline M S (APTES) & $\mathrm{X}$ & $\begin{array}{l}\text { Silanization 20\% APTES, 80\% ethanol and hydrofluoric acid } \\
\text { till pH 4, deionized water }\end{array}$ \\
\hline M S (TEOS) & $\mathrm{X}$ & $\begin{array}{l}\text { Silanization 20\% TEOS, 80\% ethanol and Hydrofluoric acid till } \\
\text { pH 4, deionized water }\end{array}$ \\
\hline $\begin{array}{c}\text { M Sol (TEOS) } \\
\text { M Sol (TEOS) } \\
\text { ZnO }\end{array}$ & $\mathrm{X}$ & $\begin{array}{l}\text { Sol-gel method 1M TEOS, ethanol and Hydrofluoric acid till pH } \\
\text { 2, deionized water }\end{array}$ \\
\hline $\begin{array}{c}\text { M Sol (TEOS) } \\
\text { ZAD }\end{array}$ & $\mathrm{X}$ & $\begin{array}{l}\text { Sol-gel method 1M TEOS, ethanol and Hydrofluoric acid till } \mathrm{pH} \\
\text { 2, deionized water, 2 wt\% Zinc oxide nanoparticles }\end{array}$ \\
\hline
\end{tabular}

The waste was shaken four times in a sieve shaker A059-11/AE/0062 by the standard LVS EN 933 (111) with vibration duration of 420 seconds and intensity of 80 per minute using $1000 \mu \mathrm{m}, 500$ $\mu \mathrm{m}, 355 \mu \mathrm{m}, 150 \mu \mathrm{m}, 90 \mu \mathrm{m}$ sieves.

Composites with the fibre content $40 \mathrm{wt} \%$ using LLDPE grade 6201XR as the matrix were prepared by the two roll mill $\left(T=150^{\circ} \mathrm{C}, t=10 \mathrm{~min}\right)$. The tensile tests were measured on the material testing machine Tinius Olsen 25ST by the standard ASTM D $638 \mathrm{M}-3$. 


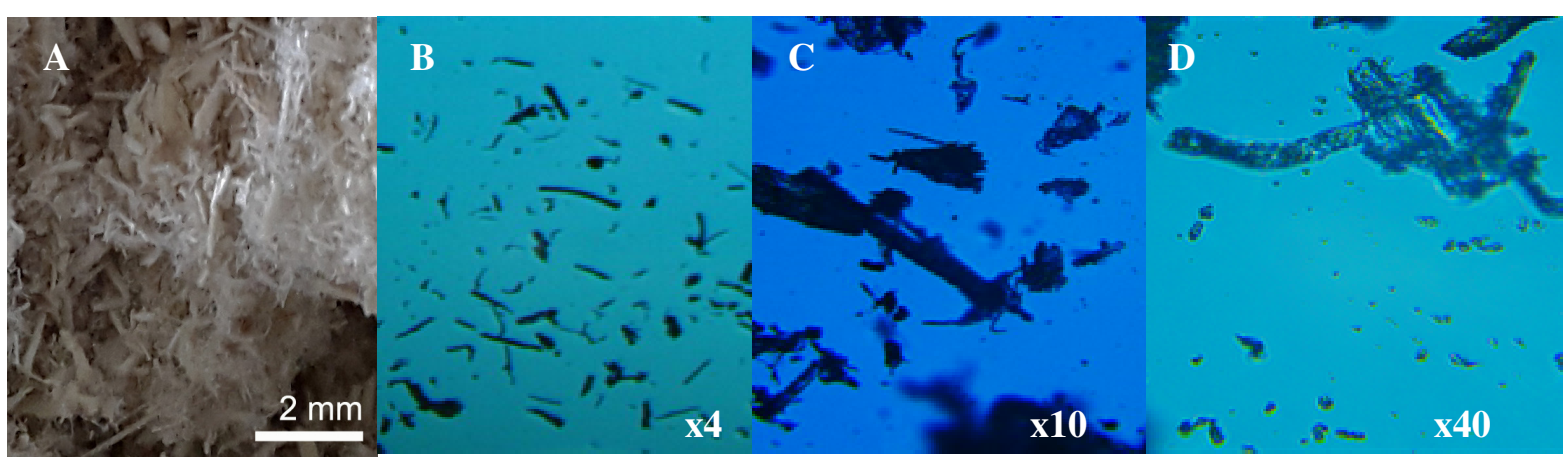

Fig. 1. Grinded hemp waste: A-particle size $\geq 1000 \mu \mathrm{m}, \mathrm{B}-\mathrm{D}$ - particle size $\leq 90 \mu \mathrm{m}$

\section{Results and discussion}

Mercerization pre-treatment increases the waste size distribution in the range $355-1000 \mu \mathrm{m}$ by 3-4 \% but decreases in the range $150 \mu \mathrm{m}$ and smaller by 1-4 \% in comparison with untreated grinded waste particle distribution. Following silanization by TEOS increases the waste size distribution in the range $150-500 \mu \mathrm{m}$ by $2-3 \%$. Graphs of Fig. 2 show that alkali pretreatment alone and in combination with following silanization do not change in total substantially processed waste particle size distribution.

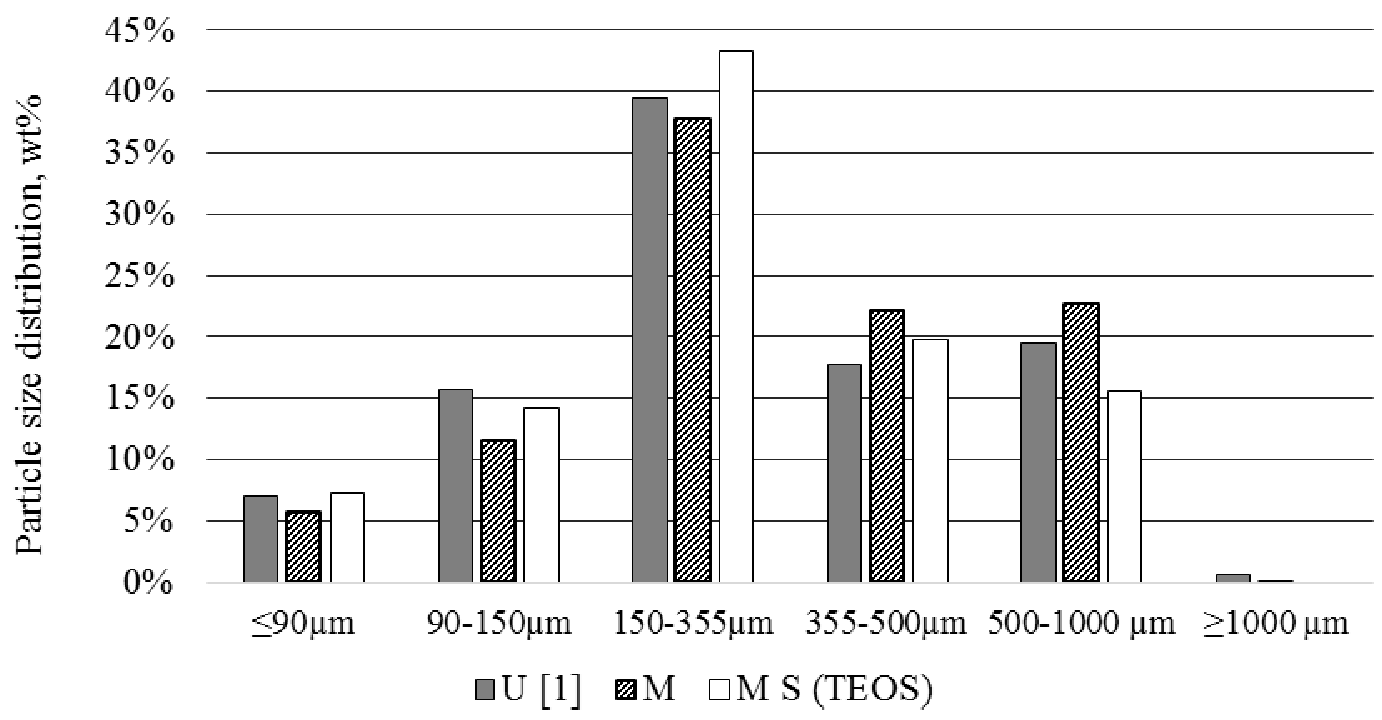

Fig. 2. Grinded hemp waste particle size distribution after alkali pre-treatment and following silanization by TEOS: $\mathrm{U}$ - untreated; $\mathrm{M}$ - mercerized; $\mathrm{S}$ - silanised

Comparing the silanization and sol-gel method impact on the fibre length distribution we can see that the sol gel method significantly increases smaller waste size formation in the grinding process. The silanised waste particle modal size distribution is $43 \%$ in the range $150-355 \mu \mathrm{m}$, but modified by the sol-gel method in the range $90 \mu \mathrm{m}$ and smaller (43 wt \%), and together with the next two intervals $95 \%$ of particles sizes fall in a size range from 0 to $355 \mu \mathrm{m}$, Fig. 3. Such a size distribution of the differences could lead to differences in the $\mathrm{pH}$ of the two treatment methods. A lower $\mathrm{pH}$ can cause fibre reduction in the mechanical properties, the grinding centrifugal force easier decomposes waste into smaller particles.

In the result of TEOS sol modification with the $\mathrm{ZnO}$ nanoparticles the distribution center moves to the small size particle range with a mode $\leq 90 \mu \mathrm{m}$. Similar as in the case of the sol gel treatment without a modifier, the volume share of three main particle size intervals drops slightly from 95 to $93 \%$ and covers the same size range 0-355 $\mu \mathrm{m}$ (Fig. 4 and Table 2).

With zinc acetate dihydrate use as the TEOS sol modifier the waste particle size distribution tends to be more symmetric with the modal interval $150-355 \mu \mathrm{m}(39 \%)$. Comparison with the waste particle size distribution of untreated waste shows three main size groups covering the size range from 150 to $1000 \mu \mathrm{m}(77 \%)$. After treatment with TEOS sol modified by Zinc acetate dihydrate three main size 
groups fall in a size range 0-355 (75\%) testifying that modifications at nano-level lead to the smaller particle sizes after grinding. As seen from Table 2, increase of smaller size particles the share tensile strength of the composite decreases.

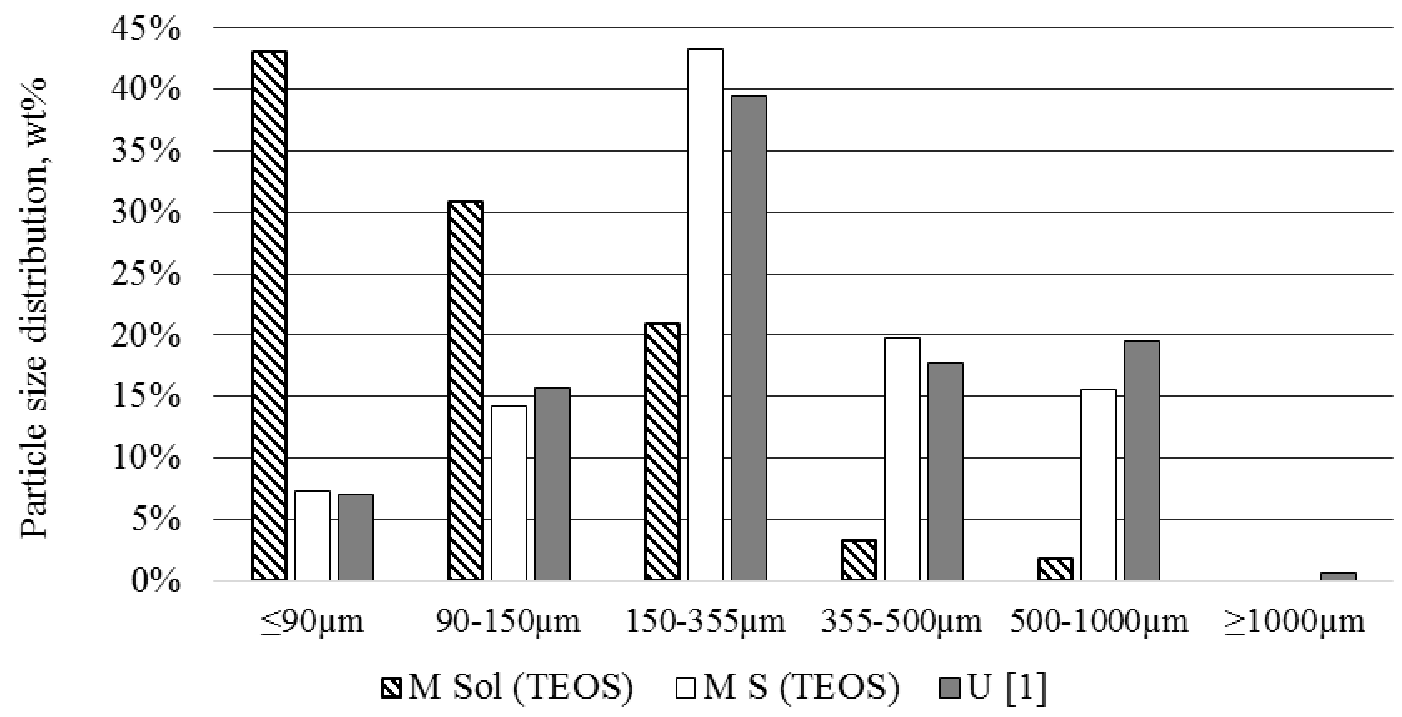

Fig. 3. Influence of hemp waste silanization with TEOS and treatment with TEOS sol on grinded particle size distribution: $\mathrm{U}$ - untreated; $\mathrm{M}$ - mercerized; S - silanised; Sol - by sol-gel method

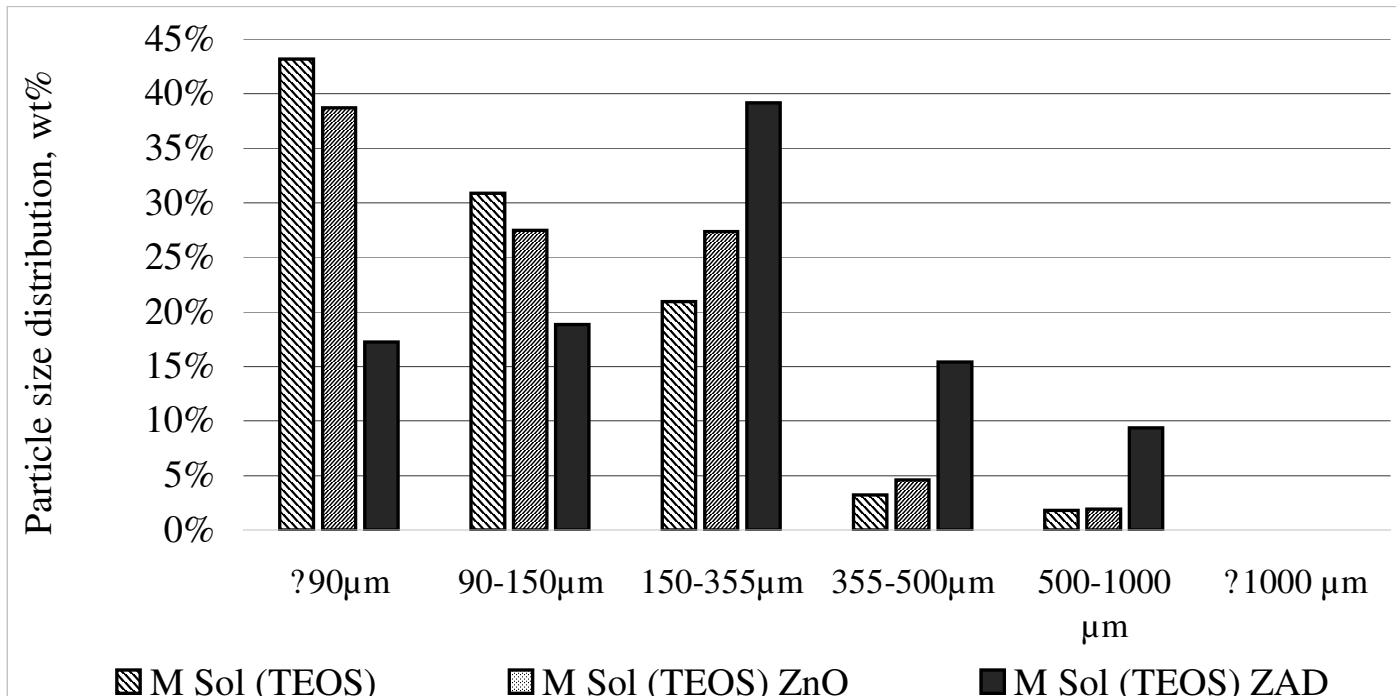

Fig. 4. TEOS sol modifier effect on hemp waste particle size distribution:

$\mathrm{U}$ - untreated; $\mathrm{M}$ - mercerized; Sol - by sol-gel method; $\mathrm{ZnO}$ - sol modified by zinc oxide nanoparticles; ZAD - sol modified by zinc acetate dehydrate

The particle length distribution is primarily characterizing the effect of composite manufacturing processes on the particle length attrition. This would also be helpful in determining the mechanical properties of the resultant composite [10].

Comparison of untreated waste modal distribution and mercerized shows that $2 \%$ difference does not affect the maximum tensile strength. The waste size decrease in the grinding process using the sol gel method may indicate a reduction in the waste mechanical properties by acidic solution $\mathrm{pH}$. Hemp is resistant to bases and only strong acid can destroy the structure [11].

The maximum tensile strength increases by $7 \%$ using APTES in comparison with the untreated waste composite (Fig. 5 and Table 2). The waste particle size distribution modal values of the both silanized samples are in the range 150-355 $\mu \mathrm{m}$, Fig.6. The maximum tensile strength of the composite with the TEOS silanized waste decreases by $0.4 \mathrm{MPa}$, but for the composite with APTES silanized 
waste it increases by $0.4 \mathrm{MPa}$ compared with untreated waste, which may be due to the formation of a longer link between the matrix and the silane layer formed by APTES amino groups.

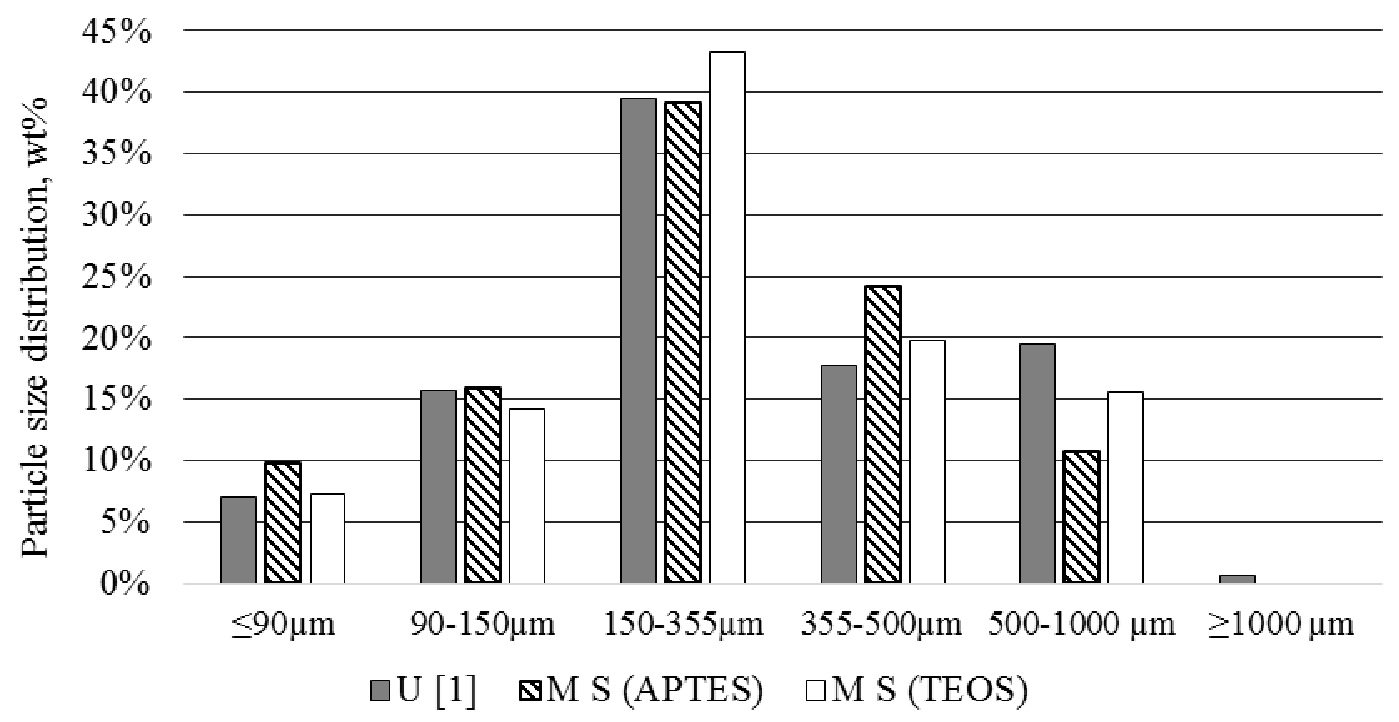

Fig. 5. TEOS and APTES silanisation effect on hemp waste particle size distribution: $\mathrm{U}$ - untreated; $\mathrm{M}$ - mercerized; $\mathrm{S}$ - silanised

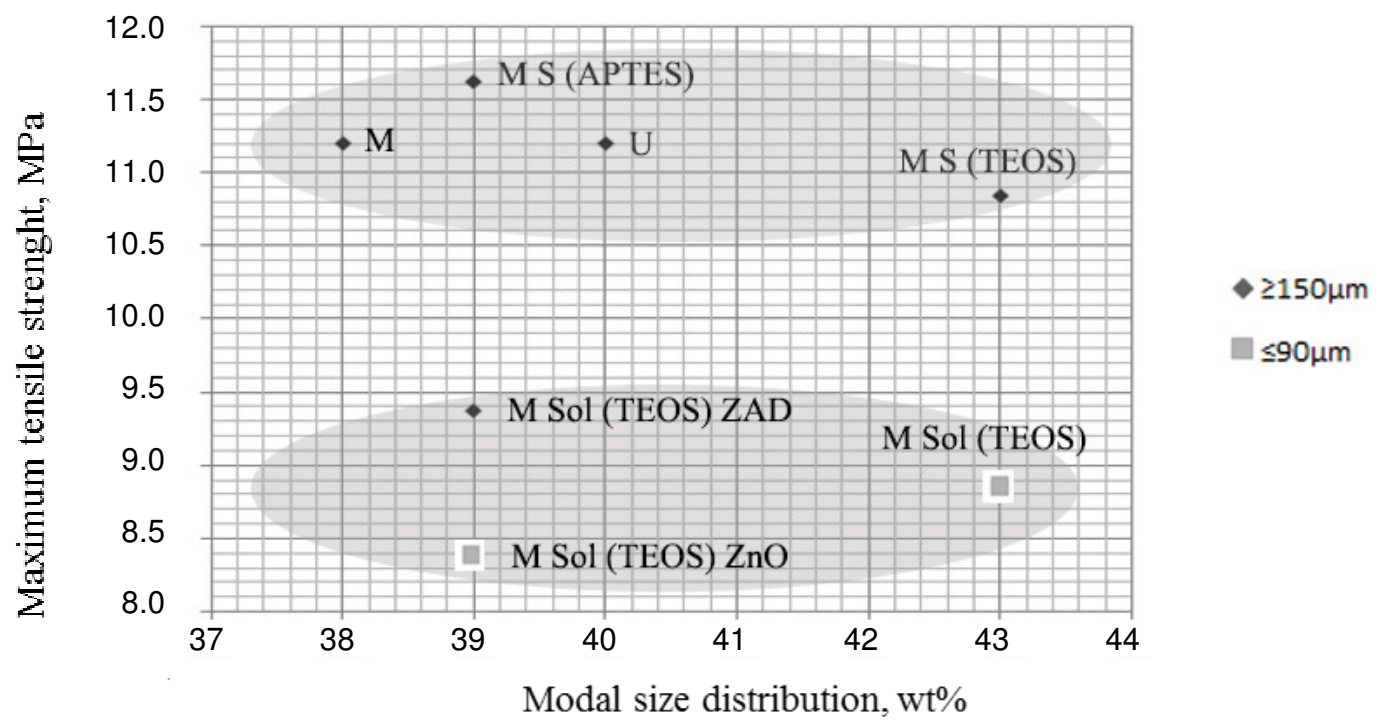

Fig. $6.40 \mathrm{wt} \%$ waste/LLDPE composite maximum tensile strength and modal waste particle size distribution correlation: $\mathrm{U}$ - untreated; $\mathrm{M}$ - mercerized; $\mathrm{S}$ - silanised; Sol - by sol-gel method; $\mathrm{ZnO}$ - sol modified by zinc oxide nanoparticles; ZAD - sol modified by zinc acetate dehydrate

Table 2

Hemp waste size distribution parameters and composite tensile strength

\begin{tabular}{|c|c|c|c|c|c|c|c|}
\hline Parameter & $\mathbf{U}$ & $\mathbf{M}$ & $\begin{array}{c}\text { M S } \\
\text { (APTES) }\end{array}$ & $\begin{array}{c}\text { M S } \\
\text { (TEOS) }\end{array}$ & $\begin{array}{c}\text { M Sol } \\
\text { (TEOS) }\end{array}$ & $\begin{array}{c}\text { M Sol } \\
\text { (TEOS) } \\
\text { ZnO }\end{array}$ & $\begin{array}{c}\text { M Sol } \\
\text { (TEOS) } \\
\text { ZAD }\end{array}$ \\
\hline $\begin{array}{c}\text { Modal size } \\
\text { distribution, wt } \%\end{array}$ & $40 \%$ & $38 \%$ & $39 \%$ & $43 \%$ & $43 \%$ & $39 \%$ & $39 \%$ \\
\hline $\begin{array}{c}\text { Modal particle } \\
\text { size, } \mu \mathrm{m}\end{array}$ & $150-355[7]$ & $150-355$ & $150-355$ & $150-355$ & $\leq 90$ & $\leq 90$ & $150-355$ \\
\hline $\begin{array}{c}\text { Maximum tensile } \\
\text { strenght, Mpa }\end{array}$ & $11.2 \pm 1$ & $11.2 \pm 1.1$ & $11.6 \pm 0.6$ & $10.8 \pm 0.9$ & $8.9 \pm 0.3$ & $8.4 \pm 0.5$ & $9.4 \pm 0.6$ \\
\hline
\end{tabular}


The correlation analysis shows positive correlation of the NFC tensile strength with the average particle size $(R=0.88)$ and modal size $(R=0.8)$. Negative correlation coefficient $(R=-0.68)$ between the tensile strength and particle concentration into three main size groups make think that differences of particle sizes in a wider range could improve the tensile strength of hemp waste particle filled composite.

\section{Conclusions}

1. The majority of the total particle mass comes from the modal and two next classes to the modal one. The share of modal particle mass of all grinded waste samples is similar 38-41\%, but lower maximum tensile strength shows composites with modal particle sizes less than $90 \mu \mathrm{m}$.

2. The particle size distribution of hemp waste treated with TEOS sol and TEOS sol modified by $\mathrm{ZnO}$ shows strong left hand asymmetry with small size particle prevalence leading to substantial decrease of the tensile strength. For waste treated with TEOS sol modified by Zinc acetate dehydrate the particle size distribution tends to be symmetric with a light tendency to the left hand asymmetry. That leads to the increase of the maximum tensile strength by $12 \%$ compared with the waste treated with $\mathrm{ZnO}$ modified sol.

3. $2 \%$ alkali treatment does not significantly affect the waste particle size distribution and the tensile strength at break after grinding with $1 \mathrm{~mm}$ grid.

4. Waste silanization with APTES allows increasing the tensile strength of NFC by $3.4 \%$, but silanization with TEOS decreasing by $3.7 \%$ compared with untreated waste NFC.

\section{References}

1. Peltola H., Madsen Bo, Joffe R. and Nättinen K. Experimental Study of Fibre Length and Orientation in Injection Molded Natural Fibre/Starch Acetate Composites. Advances in Materials Science and Engineering, vol. 2011, 2011, Article ID 891940, 7 p.

2. Kabir M.M., Wang H., Lau K.T., Cardona F. Chemical treatments on plant-based natural fibre reinforced polymer composites: An overview. Natural Materials in Composites Engineering, Composites Part B: Engineering, vol. 43, issue 7, 2012, pp. 2883-2892.

3. A guidebook to particle size analysis. Horiba scientific [online] [24.01.2017] Available at: https://www.horiba.com/fileadmin/uploads/Scientific/Documents/PSA/PSA_Guidebook.pdf

4. Zarei A. Characterization of Szego-milled Hemp Fibres. Master work of Applied Science, Department of Chemical Engineering and Applied Chemistry, University of Toronto, 2010.

5. Chapter 17. Composites [online] [24.01.2017] Available at: http://www.virginia.edu/bohr/ mse209/chapter17.htm

6. Stark N. M., Rowlands R. E. Effects of Wood Fibre Characteristic on Mechanical Properties of Wood/Polypropylene Composites, Wood and Fibre Science, vol. 35(2), 2003, pp. 167-174.

7. Nestore O., Kajaks J., Reihmane S., Vancoviča I. Physical and Mechanical Properties of Composites Based on Linear Low Density Polyethylene (LLDPE) and Natural Fibre Waste. Mechanics of Composite Materials, vol.48, issue 6, 2013, pp. 619.-628.

8. Zelca Z., Kukle S., Kajaks J. The Hemp Primary Processing Waste and Linear Low Density Polyethylene Composite. Conference Proceedings of Energy and Clean Technologies: Recycling, Air Pollution and Climate Change, 2-5 November, 2016, Austria, Vienna, pp. 55-60.

9. Vihodceva S., Kukle S. Dipping Time Influence on the UV Properties of Natural Textiles Treated via Sol-gel Method. Proceedings of the International Conference "Nanomaterials: Applications and Properties", 16-21 September, 2013, Alushta, Ukraina, pp. 1-4.

10. Bouafif H., Koubaa A., Perre P., Cloutier A. Effects of Composite Processing Methods on Wood Particle Development and Length Distribution: Consequences on Mechanical Properties of Wood-Thermoplastic Composites. Wood and Fibre Science, vol. 42(1), 2010, pp. 62-70.

11. Frank R.R. Bast and other plant fibres. Woodhead publishing in textiles. Cambridge England: The textile institute, CRC Press, 2005. pp. 352-367. 